tumours ( 7 at the site of the drug application). Tumour types included squamous cell carcinoma, cutaneous sarcoma and malignant melanoma. For pimecrolimus, 10 postmarketing cases of cancer were reported, involving 4 children ( 3 less than 6 years of age) and 6 adults. Of the 10 cases, 6 involved cutaneous tumours and 4 were lymphomas. Diagnoses were made 7-300 days after treatment was started (median time to diagnosis was 90 days).

What to do: As second-line agents, these drugs should be used only if other therapies (topical corticosteroids, emollients) are ineffective or inap- propriate. They should not be used by patients with weakened or compromised immune systems, by children under the age of 2 or by patients with active viral skin infections. Short-term or intermittent use is advised. Unfortunately, atopic dermatitis is an uncomfortable, common and chronic condition. Patients should be warned of the potential cancer risk and carefully monitored clinically when taking the drugs. Any patient with nonresolving lymphadenopathy should be appropriately investigated. The lowest concentration of the drugs needed to control a patient's symptoms should be used. Unnecessary and potentially harmful ultraviolet expo- sure (from the sun and tanning beds) should be avoided.

Eric Wooltorton

Associate Editor, CMAJ

\section{References}

1. US Food and Drug Administration. FDA Public Health Advisory: Elidel (pimecrolimus) cream and Protopic (tacrolimus) ointment. 2005 Mar 10 Available at: www.fda.gov/medwatch /SAFETY/2005/safety05.htm\#Elidel (accessed 2005 Mar 30).

2. Ashcroft DM, Dimmock P, Garside R, Stein K, Williams HC. Efficacy and tolerability of topical pimecrolimus and tacrolimus in the treatment of atopic dermatitis: meta-analysis of randomized controlled trials. $B M \mathcal{F}$ 2005;330:516-22.

3. Niwa Y, Terashima T, Sumi H. Topical application of the immunosuppressant tacrolimus accelerates carcinogenesis in mouse skin. $\mathrm{Br} 7$ Dermatol 2003;149:960-7.

\title{
IN THE LITERATURE
}

\section{Does coronary revascularization before major vascular surgery decrease mortality?}

McFalls EO, Ward HB, Moritz TE, Goldman S, Krupski WC, Littooy $\mathrm{F}$, et al. Coronary-artery revascularization before elective major vascular surgery. N Engl J Med 2004;351(27):2795-804.

Background: Evidence gathered over the last 30 years has permitted stratification of patients undergoing noncardiac surgery into categories of high, intermediate and low cardiac risk $^{1-3}$ and clarified the effectiveness of medical interventions, princi perioperative complications. ${ }^{4}$ However, until now, the benefit of preoperative coronary revascularization (through percutaneous angioplasty or bypass surgery) has not been studied in

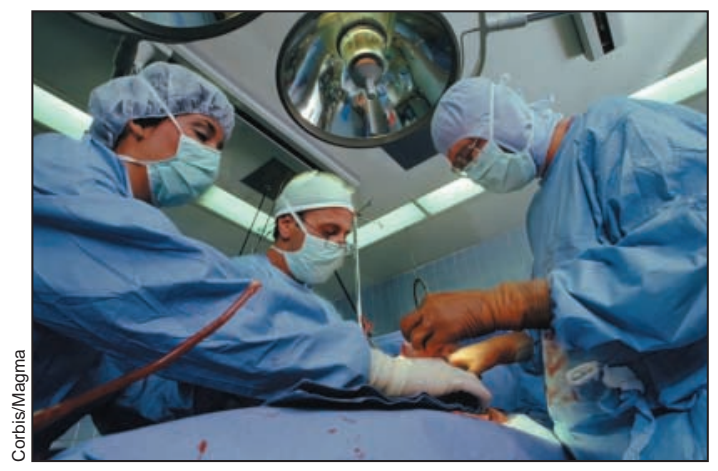

a randomized trial. Guidelines recommend conservative management for patients with stable coronary artery disease and lowrisk coronary anatomy, ${ }^{5}$ but practice variation occurs. This important addition to an evidence-based approach to the management of such patients.

Design: This study enrolled 510 patients from 18 US Veterans Affairs medical centres (98\% male) between 1997 and 2003 . Subjects were scheduled for elective vascular surgery $(33 \%$ for an expanding abdominal aneurysm, $67 \%$ for symptomatic arterial occlusive disease of the legs). To receive cardiac catheterization, patients had to be deemed at increased risk of perioperative cardiac complications by a cardiologist. Those who had angiographic evidence of stenosis greater than $70 \%$ in at least 1 coronary artery were elirandomized trial is therefore an gible. Exclusion criteria included severe coexisting illness, previous revascularization without evidence of recurrent ischemia, stenosis greater than $50 \%$ of the left main coronary artery, a left ventricular ejection fraction of less than $20 \%$ and severe aortic stenosis. Patients were randomly assigned to coronary artery revascularization (CAR) before surgery or to no revascularization. Percutaneous coronary intervention was performed on $59 \%$ of the patients and coronary artery bypass surgery on $41 \%$. The primary end point was long-term mortality, with a minimum followup of 1 year and a median follow-up of slightly over 2.5 years.

Results: Of the study patients, $74 \%$ demonstrated a moderate or large reversible defect on stress imaging or were considered to be at intermediate or high cardiac risk according to the criteria of Eagle $^{5}$ or Lee and associates. $^{2}$ Before vascular surgery, there were 10 deaths in the CAR group and 1 death in 
the no-CAR group. However, 30 -day mortality was similar in both groups (3.1\% and 3.4\% respectively). At a median of 2.7 years after randomization, mortality was $22 \%$ and $23 \%$ for the CAR and no-CAR groups respectively (relative risk 0.98 , confidence interval $0.70-1.37$ ). There were no differences in 30 -day postoperative myocardial infarction rates between the 2 groups. Patients assigned to CAR had a significant delay before receiving their vascular surgery procedure. An attempt to identify whether high-risk subjects within the study group might benefit more from CAR revealed no significant findings.

Commentary: This large and well-designed randomized study provides strong evidence in support of the recommendation against prophylactic coronary revascularization in patients with stable coronary artery disease scheduled to undergo elective major vascular surgery.

The limitations of this study include its lack of generalizability given the predominance of male patients and exclusion of patients with known left main coronary artery disease, severe aortic stenosis and left ventricular dysfuntion. Further, although the study included patients who would be deemed high risk using clinical risk scores, it lacked sufficient power to determine whether the intervention would help them. Finally, the trial lacked long-term follow-up. As the authors note, previous work has shown that bypass surgery is superior to percutaneous intervention after 5 years among patients with multivessel disease and diabetes. It is possible that high-risk patients scheduled to undergo preoperative vascular surgery, particularly those with diabetes, may benefit from surgical revascularization. Confirming this would require a much more specific randomized trial.

Practice implications: The results of this study support current guidelines by providing strong evidence that prophylactic coronary revascularization before elective major vascular surgery does not improve longterm survival of patients with stable coronary artery disease. Clinicians should be reassured that patients with apparently stable coronary artery disease, who are appropriately treated with $\beta$ blockers, antiplatelet agents, angiotensin-converting-enzyme inhibitors and statins, do not require preoperative revascularization. Despite the plethora of coronary screening tests available for such patients, physicians should also be reassured that their clinical judgement may still be the most important tool in determining stability of coronary artery disease and which, if any, patients must be screened and by what method.

\section{Mark Otto Baerlocher}

Allan S. Detsky

Division of General Internal

Medicine

University of Toronto

Toronto, Ont.

\section{References}

1. Detsky AS, Abrams HB, McLaughlin JR, Drucker DJ, Sasson Z, Johnston N, et al. Predicting cardiac complications in patients undergoing non-cardiac surgery. 7 Gen Intern Med 1986;1:211-9.

2. Lee TH, Marcantonio ER, Mangione CM, Thomas EJ, Polanczyk CA, Cook EF, et al. Derivation and prospective validation of a simple index for prediction of cardiac risk of major noncardiac surgery. Circulation 1999; 100:1043-9.

3. Goldman L, Caldera DL, Nussbaum SR, Southwick FS, Krogstad D, Murray $\mathrm{B}$, et al. Multifactorial index of cardiac risk in noncardiac surgical procedures. N Engl f Med 1977;297: 845-50.

4. Mangano DT, Layug EL, Wallace A, Tateo I. Effect of atenolol on mortality and cardiovascular morbidity after noncardiac surgery. Multicenter Study of Perioperative Ischemia Research Group. N Engl 7 Med 1996;35: 1713-20.

5. Eagle KA, Berger PB, Calkins H, Chaitman BR, Ewy GA, Fleischmann $\mathrm{KE}$, et al. ACC/AHA guideline update for perioperative cardiovascular evaluation for noncardiac surgery executive summary: a report of the American College of Cardiology/ American Heart Association Task Force on Practice Guidelines (Committee to Update the 1996 Guidelines on Perioperative Cardiovascular Evaluation for Noncardiac Surgery). $7 \mathrm{Am}$ Coll Cardiol 2002;39(3):542-53. 